\title{
Moments of becoming: Experiences of embodied connection to place in arts-based service learning in Australia
}

Anne Power Western Sydney University

Dawn Bennett Curtin University

\section{Acknowledgements}

Support for this project has been provided by the Australian Government's Office for Learning and Teaching. The views expressed in this paper do not necessarily reflect the views of the Australian Government's Office for Learning and Teaching. The project was led by Queensland Conservatorium Griffith University in collaboration with Curtin University, The University of Western Sydney, and community partners in Central Australia and Western Australia. The project team consisted of Dr BrydieLeigh Bartleet (Queensland Conservatorium Griffith University), Professor Dawn Bennett (Curtin University), Associate Professor Anne Power (University of Western Sydney) and Dr Naomi Sunderland (Griffith University).

To cite this article: Anne Power \& Dawn Bennett (2015): Moments of becoming: experiences of embodied connection to place in arts-based service learning in Australia, Asia-Pacific Journal of Teacher Education, DOI: 10.1080/1359866X.2014.960801

To link to this article: http://dx.doi.org/10.1080/1359866X.2014.960801 


\section{Moments of becoming: Experiences of embodied connection to place in arts-based service learning in Australia}

The experience of place in arts-based service learning is personal. It can be difficult to define and challenging to share and build upon. This paper, reporting from a national arts-based service learning project involving three Australian universities, is concerned with experiences of place in forming professional teacher identity. Using a narrative methodology in presenting the stories of six people, pre-service teachers and Indigenous community members, the paper draws on a number of different theoretical frameworks to explore each participant's experience and its longer-term impact on their thinking. The participant stories revealed the value of spaces between art-making, teaching and research. The learning experiences led pre-service teachers to reflect deeply in relation to self, and to consider the impact of their experiences on both current and future professional interactions. As anticipated, participants found it difficult to communicate these elemental experiences in the written word. The findings have implications for the value of flexible and critical service learning approaches, particularly in diverse cultural contexts.

Keywords: pre-service teachers, arts-based service learning; place based learning

\section{Introduction}

The research that underpins this article involved three universities engaged in arts-based service learning with Australian Aboriginal people. The purpose of this article is to document the key learnings from a case study conducted with pre-service teachers and community members. From a larger body of participant reflections, those of four pre-service teachers and two community members provide the focus of this paper because they articulated learnings that were difficult to express. The paper draws together Ellsworth's (2005) theoretical frame of 'the coming of a knowing', the approach of arts-based service learning (Krensky \& Steffen, 2008), the arts-based research method of a/r/tography, which combines the lenses of artist, researcher and 
teacher (La Jevic \& Springgay, 2008), and the principles that enable a pedagogy of place (Somerville, 1999; 2005; 2012). With these elements as its theoretical frame, the paper examines the stories of six people: four pre-service teachers and two of the community members with whom they worked. As Mills states (2008, p. 268), "If teachers are integral to making a difference in these times of increasing student diversity, we need to find ways to improve the success of diverse students through our pre-service teacher preparation”. Nevertheless, Mills cautions against a superficial treatment of diversity in influencing attitudes in the space of one experience. We acknowledge the small number of reflections included in the paper and simply note that our research included reflection after selection for the placement, mid-way and at the end of the placement. Ethical approval was granted for all elements of data collection and reporting at each of the universities in the consortium from Griffith Human Research Ethics Committee and expedited at Curtin and the University of Western Sydney: GU Ref No: QCM/19/09/HREC.

Reflection was central to this research. Mobely $(2011$, p. 86) argues that the "roots of democratic citizenship originate both in our individual identities and our sense of shared community. There is a reciprocal relationship between diversity and democracy as the latter provides the 'moral compass' for the former". Mobely asserts that it is essential to integrate diversity into service learning and this is best achieved through "mindful service-learning" (2011, p. 89), which fosters the essential element of reflection by introducing the concept of mindfulness. This requires students to be aware of their own historical and cultural perspectives. Without reflection, Mobely argues, we risk "the opposite of mindfulness, mindlessness, [which] can lead to prejudice and stereotyping" (2011, p. 90). 
Much of the existing literature emphasises projects that take students far away from their familiar lives and locales, but we do not suggest that the only 'authentic' places are those away from students' familiar milieus. Researchers have argued that an immersion experience is effective: "living in a community different from one's own increases awareness of the experience of being 'other"' (Walsh \& De Joseph 2003, p. 269). However, whilst immersion experiences can undoubtedly be transformative (Kiely 2004), a smaller body of literature has stressed the value of all community-based learning projects, "whether placement is on a reservation, adjacent to campus, overseas, or in one's hometown" (Stachowski \& Mahan 1998, p. 160).

Whilst the pre-service teachers reported here had the opportunity to experience a remote community and its people, we were mindful not to reinforce a view that " 'real' Aboriginal communities only exist in rural and remote areas... a reminder of how invisible our communities are to the people who live and work side-by-side with us" (Behrendt, 2006, n. p). Moreover we were careful to ensure that pre-service teachers would be able to apply the learning from their remote experiences to their urban lives and work, recognizing that about $60 \%$ of Aboriginal and Torres Strait Islander people live in urban communities (Australian Bureau of Statistics, 2011).

The context of this study is Australia and our work is with Australia's first peoples; however, we do not suggest that Aboriginal knowledge holders are the only people authentically and intrinsically connected with place. In defining traditional knowledge, UNESCO warns of such common misperceptions and cautions that many holders of traditional knowledge are not Indigenous. At the same time the definition is helpful: It is intimately tied to language, social relations, spirituality and worldview, and is generally held collectively. (UNESCO, 2006, n. p).

In a real sense Gorringe (2010) expressed a connection between Aboriginal values and the philosophical ideas that have guided this research. His insistence that there are 
many ways, aside from neo-liberal concerns of financial sustainability, of seeing and valuing relationships to one another, and to country, echoed our own feelings about how service-learning projects with Australian Aboriginal communities might be valued and sustained within Australian higher education institutions.

In order to conduct the research, ethical procedures (H9619) were conducted at the universities in the consortium researching 'Enhancing First Nations Content in the performing arts in tertiary institutions through service learning.' Pre-service teachers, their supervisors at the schools, and First Nations community members at the Language Centre and the Music Centre, all completed consent forms. Only those participants who freely gave consent had their stories recorded.

Aboriginal people, land and culture are entwined, and we begin with a description designed to open a connection with place-based experiences. The description concerns an evening in Likkiparda, north of Tennant Creek in Australia's Northern Territory, where one of the researchers had travelled with pre-service teachers at the invitation of Elders from the Language and Cultural Centre Papulu Aparr-Kari (PAK). The memory is associated with preparing a meal and receiving hospitality. The research journal entry is shared in the hope that sharing an individual memory will enable readers to enter the realm of social or collective memory (Darian-Smith \& Hamilton, 1994):

The kangaroo tails and potatoes in jackets were in a pit in the ground cooking on coals. Junior cooked the roo tails and talked of hunting kangaroos. And if they didn't find one, they'd go to the butcher. Pragmatic, with a sense of humour. Lynne made damper with the children, getting them to feel what it was like and talking all the time about the texture and not working it too much. The meal was generous. At the end of the meal Mrs Nixon (now deceased) spoke, welcoming her two granddaughters and introducing them to their uncle, welcoming us to country. 
In Aboriginal culture, country imbues people's thinking about who they are and have become (Moorcroft \& Galwood, 1997). Bird Rose (1996, p. 7) explains the way in which this emotional connection emerges in conversation:

People talk about country the same way that they would talk about a person: they speak to country, sing to country, visit country, worry about country, feel sorry for country, and long for country. People say that country knows, hears, smells, takes notice, takes care, is sorry or happy.

It is with this understanding of connection with country, with place, that this paper engages and frames the stories of pre-service teachers and the community members with whom they interacted. We do this through the lens of knowledge as an evolving process featuring 'moments of becoming' (Ellsworth, 2005).

\section{The coming of a knowing}

Ellsworth (2005, p. 135) asks, "What is it, then, to sense one's self in the midst of learning as experience, in the moment of learning, in the presence of a coming knowing, in this interleaving of cognition and sensation/movement?" She responds that arts-based knowing lies beyond language as something that can be "painted, sculpted, danced, or sensed in and through music, moving images, architecture and poetry" (2005, p. 157). In Ellsworth's terms, the time of the learning self is marked by moments of rapid bodily sensations and tangles of thought. Citing De Bolla (2001, p.128), who describes arts-based knowings as those that "arise from a place more elemental" than intellectual, Ellsworth (p. 158) contends that "aesthetic experience holds the potential for the coming of a knowing, available only through acknowledgement and inaccessible through explanation". For the pre-service teachers in this study, the aesthetic, arts-based service learning experiences were amplified by the experience of a place that has a wild beauty unknown in urban parts of Australia. 
Our research broadly is about positioning service learning as a strategy through which Australian higher education institutions can promote Australian Aboriginal cultural content for all tertiary students. Consonant with Molnar (2010) and others (Lawton, 2010; Russell \& Hutzel, 2007) we argue that arts based service learning in particular provides a culturally sensitive and enabling process for embedding Indigenous content.

\section{Our method}

The authors of this paper were engaged in funded arts based service learning (ABSL) research in which arts tertiary students and education pre-service teachers worked with Aboriginal communities in Tennant Creek, in Australia's Northern Territory. Tennant Creek is a township of approximately 3,500 people located 500km north of Alice Springs and 1,000km south of Darwin. At the time of writing, Tennant Creek ABSL projects have run for seven years and have involved over 67 tertiary students, including 30 arts majors and 37 pre-service teachers. Within Tennant Creek, the program has involved over 30 Indigenous artists and Elders and over 50 youth.

The paper combines a range of conceptual-theoretical resources with the voices and experiences of the pre-service teachers and two community members. Participant experiences are drawn from digital stories, diaries and interviews with pre-service teachers; interviews with community members; and fieldwork diaries prepared by the researchers. Ethical approval was granted for all elements of data collection and reporting. The researchers have community permission to present information gathered through these processes. 


\section{Conceptual frameworks}

Our research draws on the theoretical frameworks of a/r/tography, arts-based service learning and place pedagogy. A/r/tography is a relational arts-based research methodology that inquires into educational phenomenon through artistic means (La Jevic \& Springgay, 2008) and encompasses the practices of the artist, researcher and teacher. $\mathrm{A} / \mathrm{r} /$ tographical inquiry is based on openness, listening and being receptive to the other (Todd, 2003). As such, it insists on "participants having a say in how the research should be conducted". In our case the community members and pre-service teachers become artists, researchers and teachers who were fully engaged in the research process (La Jevic \& Springgay, 2008).

The nexus between art-making, research and teaching is also central to artsbased service learning (ABSL), which connects pre-service teachers and community members to promote community arts practice and to meet arts-based educational objectives (Krensky \& Steffen, 2008). In ABSL, the arts are "central to the experience as both a means to meeting community-identified needs and an end in and of themselves" (Krensky \& Steffen, 2008, p. 15). The literature on ABSL documents the benefits of facilitating expression, communication and connections between diverse participants (Jameson, Clayton \& Jaeger, 2011); evoking participants' strengths and abilities (Thomas \& Mulvey, 2008); developing empathy and compassion between participants and for other groups (Molnar, 2010); building community through “empathetic social interaction" (Jeffers, 2009, p. 19); and providing opportunities to inquire into and affirm "personal, cultural, or spiritual values" (Jeffers, 2009, p. 18).

Finally, we draw on Somerville's framework of place (Somerville, 1999; 2005; 2012), which defines three elements that are crucial to our work: namely, that our relationship to place is constituted in stories; that the body is at the centre of our experience of place; and that 'learning' a place involves a contact zone of contested 
place stories. In presenting stories from both pre-service teachers and community members we illustrate some of the ways in which embodied knowledge is shared and negotiated. The stories feature a sense of the "past interfusing with present" (Ellsworth, 2005, p. 19) as well as "selves in the making" (ibid. p.29).

\section{Experience of cultural training}

Pre-service teachers undertake a preparation week in June before their four-week block in the school and community. They consult with the community, seeking guidance about the projects to be undertaken during the October placement. During this week, they engage in cultural training with the Aunties at the Papulu Aparr-Kari (PAK) Language Centre. In Aboriginal culture, Aunties are wise women who are guardians of rules of behaviour (Robertson, Demosthenous \& Demosthenous, 2005). At the Language Centre, pre-service teachers receive a skin name and come to understand how skin names relate to the organisation of Australian Aboriginal society, ensuring that there are common understandings about ceremonial business and obligations to the land.

This training is beneficial for all pre-service teachers. Among the four preservice teachers in this paper, two are Australian Aboriginal and all four are female. The 37 pre-service teachers have included 12 males and 25 females. They have encompassed high school specialisations in English, Science, Technical and Applied Sciences, Dance and Music and primary school (elementary) generalist teachers.

\section{The stories}

The first story comes from Stacey, a Wiradjiri woman and pre-service teacher. At her initial interview, Stacey had mentioned community involvement; however, her experience in the training session at PAK was a revelation: 
The reality for me is that my family traditions have been lost and that's horrible. When we were at the language centre I could feel myself getting upset. I was in awe and so excited to be learning about skin names. As Waradjiri, not knowing if our skin names were like this, not knowing if our systems were like this, it was a reality check that it's gone. I think that makes it even more special that they are willing to share theirs with me.

Later, Stacey described the effect of the training and what it would mean into the future:

The training's validated my feelings. I can feel comfortable saying 'this is who I am'. That's been almost life changing for me. The community in which I live realise that I'm Aboriginal. In the interview, I talked about my involvement with Kurrunella Aboriginal association, but then I have a different side that is my son's public school and the soccer club. And those communities don't meet and I've kept it quiet in terms of my Aboriginality in fear of being judged. Now this experience has confirmed that it's OK. My experience has been different from my peers' because of that. At PAK yesterday I took an opportunity to talk with [Auntie] Penny, to let her know what was important to me. I see the value of making sure culture is not lost.

Stacey's experience at the Centre helped her come to terms with different parts of her world. She came to realise the importance of the survival of cultural traditions and language, both for herself and for others.

Our experience across the ABSL projects is that having a skin name immediately changes the ways in which pre-service teachers connect with a community of teachers and school students. Within this kinship system, community members become brothers, sisters, daughters, and so on, with responsibilities and obligations to the community. Stacey's “coming of a knowing” (Ellsworth 2005, p. 158) was accompanied by Ellsworth's "jumbles of thought" (ibid., p. 8) and by an "interleaving of cognition and sensation" (ibid, p. 135). She knew that her feelings about the training session differed from those of her non-Indigenous peers, and she found it difficult to put 
her feelings into words. Whilst Stacey could talk about her excitement, it was clear that she felt deeply about her own loss. This aspect she could not talk about.

Penny, one of the Elders providing the training at the Centre told of her own story of coming to work at the Centre:

I was born in Ali Curong. My grandfather's language was Wanmumpa. I speak mostly Warumungu but I was next-door neighbour to Wanmumpa. I could translate for each of them. That's how I became involved with Warumungu people. Karen [Centre director] asked me to join the Language Centre in 1995. I knew my language and my law, so I agreed. The Centre is a resource for many different languages, where people like the student teachers can come to learn some language.

Penny's moment of becoming was her decision to commence work with the Centre, and she talked passionately about the teaching and learning of Warumungu language. In the Centre she had found a place of respect. Working with the Elders of the Centre, she had enacted her passion through cross-generational programs between the high school and primary school, promoting the Warumungu language:

In the cross-generational [program], the high school students teach Warumungu language to a whole group of primary school children. The children go back and tell their parents or their grandmother. The children might also ask, 'I want to be able to speak my language.' In this way, teaching the kids reaches the parents.

Some of the parents don't speak their own language, so it's trying to re-establish that. The old people taught us and now we teach our children. The young people have various places in town where they can learn things from the old women about medicine and about speaking and writing language. Some of the younger generation have families that still go out to homelands. They go and learn the old way of culture. They talk language to their young women or young blokes. Some might talk a different language but they teach Warumungu. 
Penny described her commitment to protecting the land. Her 'coming of a knowing' is demonstrated in her acknowledgement of her role at the Centre, her connection with the old people, the old way of culture, and her protection of the land:

Where I grew up there are sacred sites. That's the Dog Dreaming. I'm Kadish from my grandfather's country at Mukaty. So I've been involved in the protest about nuclear waste. If it's in one part of the country it's going to travel with just one spill. I fight against nuclear waste because it's my country.

As seen in the text, Penny views herself as a communication carrier between the old and young people, and between her community and non-Aboriginal people. She knows what she can share of the stories and traditions: for example, she can talk about Mukaty because it is her country and needs protection.

Tradition and land were also central to the story told by Auntie Heather, who initiated a language and culture program at Elliott school, $252 \mathrm{~km}$ north of Tennant Creek:

I want it to be a strong language and culture program. I need to explain some of the things in English first. But when I taught the students about the Overland Telegraph Line, it was done mostly in language, getting them to understand how our people confronted new people coming in to our territory. I spent a lot of time reading information about how they brought the Line through the territory, made their way across. I did a drawing for one pole supporting the Line. I wanted them to understand that when they started they only had one pole for the wire. Our people used to call it the wire trail then. Because it was done a long time ago, it was only our people that were in the country. For the people that laid out the Telegraph, it was the first time they'd seen the country and travelled through it, through its trees and plants and mountains and hills. They had to find where it was safe for them to travel through.

Auntie Heather's moment of becoming was her long journey of becoming a teacher: 
I grew up in Queensland and went to school there. I did my first teaching at a place called Macarthur River, near the Gulf [of Carpentaria]. Then I came up here [to Elliott] and there was a job for an assistant. I applied for it and worked for nine years as assistant. This was my dad's country. When I came up here, a lot of the old people that I met, we used to go out for culture trips with the school. They used to get me to say words that I didn't know. Then I learned. And when I worked for nine years I got a chance to do a teacher's course.

The community members' focus on reaffirming and recreating forms of cultural knowledge that nurture and protect people is strongly connected to Gruenewald's (2003) idea of reinhabitation. It is also part of Tacey's (1995) writing about the deep world of the psyche, which is the 'nature' inside us and is directly influenced by the forces of 'nature' outside us. The idea of place as an organising principle and framework of research has a noteworthy pedigree among both Indigenous and nonIndigenous Australian scholars (Muecke, 1984; Bird Rose, 2000; Somerville, 1999). The strong associations with place emerge once again when Auntie Heather talks of the lake close to where she teaches:

The lake here has a strong meaning. When we learn about our custodians, we learn of the people in charge of our ceremonies and songs and the country that they looked after. The old people are still there. But we are also doing it together. We all have a responsibility for one part we have to look after. Some of the families go out to the lake. The kids are learning when they're spending time out there with their parents. Some of them might be lucky and have picked up their own language. We had a program back in the $90 \mathrm{~s}$ in language. Some of their mums and dads might have been in that. Then we didn't have it going for about 10 or 15 years. Since we've begun again I was able to talk about the animals and the birds and I can tell the kids how we are related to them and how animals became our totems.

Auntie Heather also emphasises the importance of place when teaching children about cultural knowledge: 
Some of them would go back to their country, mother's or grandmother's country, all of their dreaming places. I've explained how some of the kids are related to the eagle. When we talked about the universe, night and day, we looked at the Milky Way. We went out for a trip one day to the airstrip and asked a couple of old ladies about a story. Then they told us a little about the eagle. There are two shadows in the sky and they say it's the two eagles, underneath the Southern Cross. Our people tell a story about that Milky Way. It's a road in the sky. If they didn't know their direction, they knew the emu walked first on that road in the sky.

Finally, Auntie Heather stresses the importance of oral tradition and intergenerational learning:

I've learned a lot of things when I was young orally, by looking and learning what our people taught us. We had to keep it in our minds and remember things we had to do. We learned things like respecting our people and our country. These young kids need to learn more about our culture. We need to take care of everything, the country. I'm trying to get the kids to learn some things orally, too. I realise the kids need to know some of these names now. One of the old people said to me: "These kids should be learning a lot of things out in the bush".

Auntie Heather's 'coming of a knowing' is evident in her own thirst for knowledge that is always grounded in "sensing the self" (Ellsworth, 2005, p. 135). She knew the strategies that engage learners before she completed her teacher's course. She understood the power of 'doing together' in custodianship of the land. She wanted to involve the next generation of learners in that process, and in her teaching she gathered and shared the stories that were important to the children of her community.

For the pre-service teachers, the moment of becoming was a transformative experience through their embodied connection to place and their connection to the people of the place. In line with Lacan's (1977) notion of 'infancy' - moments of becoming that project the individual's formation into an event they make happen - the 
pre-service teachers experienced multiple moments of becoming. Pre-service English teacher Lisa reflected:

I've tried to explain what it's like to work out here. I don't know whether it's possible to capture it, as so much is interpersonal. So much of it is about building relationships with students in school and then seeing them in the community. The desire to be part of that community would be really hard to share. It's so different physically teaching is different. The school environment is different. It would be good to show the resourcing. It would be good to show the way kids react to teaching, such as the amazing participation you see in the music room. It would be good to show the way kids behave differently - there's an entirely different culture. I think the language to describe it is really limited.

Pre-service teacher Sharni had interesting glimpses of both traditional and contemporary culture when she was teaching a dance class:

I've always been really interested in traditional dance. Yesterday, I was teaching a dance to Year 11s to warm up and one of the boys broke out in some traditional dance moves. I didn't expect it from him. He'd only shown interest in basketball before. He did a kangaroo move and an emu move and I told him that it looked so good.

Victoria, a pre-service visual arts teacher, had a rich experience of connecting with a student. That was a moment of becoming for her:

In Western Sydney there are Indigenous kids in classes but the particular ways they do things can easily be swamped by louder kids or different kids. Now I'm looking to see that 'particular way'. I think already I've had a glimpse when I was working with one Year 10 student. Initially she appeared disinterested but when we started talking about animals that she had to put into an eco-systems poster, she got very excited. When she sprang into action to look for a fish, she seemed to know a lot about them. I started to do an Internet search but she took over, saying: 'No, no, if I see it I'll know what it is.' She searched for a good few minutes till she found a picture of a carp. She seemed to know a lot about plants, animals and fish. I got the sense that it was cultural knowledge. She also knew their language names. 
It all happened when I said I came from the Blue Mountains near the bush. All of a sudden we were best buddies, because I lived somewhere there were animals, I wasn't just a person from the city. There was some 'thing' she was drawing on. If I can know something about how to connect with Indigenous kids and what sort of things they're interested in, everything goes in a way that's much more productive. I hit a trigger with her. I don't yet know how to operate that trigger in another context but I saw what happened when it worked.

Knowing how to interpret complex observations in the classroom takes time, and her time with Indigenous students enabled Victoria to unpack cultural differences that she had previously been unable to analyse:

It looks like there is nothing going on and there is actually learning stuff happening. The deceptive nature of the 'passive' classroom. I suppose I'm looking for the content of silence or stillness. Having come from a really busy school, this has been a complete gear shift. To try to listen in the spaces. I found that the kids here warm to you gradually. One girl had been told by her friends she had dinosaur toes. She wanted to talk to me and she was looking for a way to do it. When I agreed with her friends about her toes, she loved that I'd joined in the joke. First watching, looking for a way to make contact. I found that also among the refugee kids I've taught. They'll look at you sideways and then ask if you've got a tissue. That's how it starts. Something innocuous. These Indigenous kids seem like that. And a certain curiosity. Who you are and what you've done to get to here.

Victoria reflected on the changes this learning had evoked in her:

It's listening, looking around you. It's almost like you're in a different sensory mode. That's what it feels like. It's not like a big intellectual shift. Again I think that comes back to silence and space. You need to shut down a hyper awareness of things and listen through yourself. It's almost like a kind of meditation, letting things flow, not trying to grab on to anything. It's connected to mindfulness, that's the nearest I can get. It's a tuning in to your environment.

For these pre-service teachers, the 'coming of a knowing' was as De Bolla (2001) described, more elemental than intellectual. In their reflections, the pre-service 
teachers struggled to find the words to explain what they were learning and becoming. They observed the different participation of the school students and the ways in which students stepped between traditional and contemporary culture. They observed when they 'hit a trigger' with students and tried to discover what it was and how it operated. They sensed content in the stillness and silence of the students, and the need to 'tune in to the environment'.

\section{Implications of the stories for arts-based service learning}

For Australians, whether Indigenous or not, the centre of the continent is a wondrous place of vibrant red earth, purple shadows as the sun sets, and unique landscapes. Yet it is in small communities such as Likkiparda, near Tennant Creek, that non-Indigenous Australians can encounter the lived expression of Indigenous connection to country. For teacher educators and pre-service teachers, this is an enduring insight. The stories of 'moments of becoming' revealed the spaces between art-making, teaching and researching. The pre-service teachers and the community members existed as bodies within a network of relations, and it was this relationality that created understandings of shared existence (Nancy, 2000).

In keeping with the relationships between artist, researcher and teacher within a/r/tography and ABSL, and the embodied learning central to Somerville's framework of place (1999), pre-service teachers were proactive in suggesting digital stories and photo collages. These, they found, enabled their experiences to move beyond the individual to something that might motivate multiple postgraduate students to a different relational understanding and the beginnings of seeing themselves on a research journey. They also acted because of a need to move away from the written word, with which they found it difficult to represent their experiences and learning. This difficulty is acknowledged by others: as Aboriginal interpreter and artist Nancy Turner (2010, p. 
15) has explained, "the only way we can translate into English how we see our relationship with the Land is with the words 'hold' and 'connect'". Aboriginal advocate and poet Judith Wright (1985, p. 32) agrees, lamenting that even the word 'landscape' is inadequate to describe the "earth-sky-water-tree-spirit-human continuum which is the cosmological and existential ground of Aboriginal Dreaming".

The pre-service teachers undoubtedly experienced changes. For example, there was the facilitation of empathy (in line with Molnar, 2010) between pre-service teacher Lisa and her students. For Lisa, this involved seeing the students both in the school and in the broader community. For Stacey and for Sharni, the arts-based service learning was about drawing on their own strengths and abilities (in line with Thomas \& Mulvey, 2008) and the ways in which they could connect with traditional and contemporary culture. For Victoria, the experience provided opportunities (in line with Jeffers, 2009) to be mindful and to inquire into spiritual values of silence, stillness and space.

\section{Concluding comments}

Having worked with tertiary students at three universities, from multiple disciplines, this paper draws its examples from the experiences of a small number of pre-service teachers and community members. We have focused on this particular cohort because of the valuable insights they communicated and the impact of their stories on our understanding of how to conduct arts-based service learning with Australian Aboriginal communities.

Whilst other forms of fieldwork may acknowledge "a reality of sharing and interaction, one predicated on negotiated relationships" (Shelemay, 1997, p. 202), service learning requires true reciprocity in the design and implementation of programs. Such forms of reciprocal engagement are complex and may be difficult to enact, given the frequent difficulties of consultation between geographically distant partners, and the 
forms of cultural distance that must be traversed by service learning collaborators. However, experiences must be both authentic and of mutual benefit to community members and participating pre-service teachers, as they develop their teacher identities and further their knowledge and cultural relationships.

We began by stating that the experience of place in arts-based service learning is personal, and that it can be difficult to communicate. This extends beyond the difficulties of expressing the experience using the written word; we argue that the true learnings from such experiences cannot be communicated second-hand, nor can they be learned out of context. McInerney, Smyth and Down (2011) write that Place Based Education (PBE) answers a need to bring schools and communities closer together, with place as a guiding principle in the choice of curriculum and teaching practice. The preservice teachers and community members in this paper demonstrated a critical perspective that disrupted ideas of responsibilities and obligations to community, connected local issues with environmental and social concerns, actively worked to maintain and reconnect with traditional languages and values for the good of the community, and searched for ways to connect in intercultural learning. Whilst this was a project undertaken in a rural location, we are confident that the learnings of the preservice teachers will be applied in multiple settings as we saw in their reflections that they made connections with experiences in urban settings. Our own learnings from the experience enable us to incorporate and communicate embodied connection to place even when students do not have the opportunity to work remotely.

Through these stories we began to understand the experiences as being akin to Ellsworth's (2005) notions of both cognition and sensation. We also found that they could be threshold learning experiences, they could be transformative, and that they could present troublesome knowledge that required time to resolve. This led pre-service 
teachers to consider the issues in relation to their own development, and in relation to both current and future professional interactions.

The stories of 'moments of becoming' revealed the spaces between art-making, teaching and research. One such space was the network of relations in which pre-service teachers and community members existed. In this sense, the findings also reverberate with Lincoln's (1995, p. 287) view of relational research as "a research grounded in the recognition and valuing of connectedness between researcher and researched".

At times, the spaces between art-making, teaching and research existed as stillness and silence. Within these spaces pre-service teachers found a content that offered new ways of understanding and being. The silence was not only the silence of not speaking; rather it was what Jaworski (1997, p. 382) describes as "a communicative resource whose manifestations go well beyond the mere absence of speech". Juxtaposition of the traditional and contemporary, Western and Indigenous, were reminiscent of Ollin's (2009, p. 25) writings on different types of silence that provide "a cultural resource enabling us to focus on the classroom as a relational space where teachers and learners interact on many different levels and where 'good' teaching involves covert as well as overt activity".

The approach adopted for this study contrasts with the more traditional practicum opportunities presented to pre-service teachers. The custodial role of the women at the Language Centre, and their connection to country as though country was a person (consistent with Bird Rose, 1996), established the idea of place as an organising principle and framework of research into self and other. As we anticipated, the preservice teachers found it challenging to communicate these often elemental experiences in the written word, and they drew upon their resources and skills to create additional modes of communication. The findings suggest that more research is needed in order to 
understand the deeper impact of arts-based service learning, particularly in diverse cultural contexts. It is in these experiences that pre-service teachers begin to learn how to negotiate the multiple cultures they will encounter in contemporary Australian life.

\section{References}

Australian Bureau of Statistics. (2011). Estimates of Aboriginal and Torres Strait Islander Australians, June 2011. 3238.0.55.001. Canberra: Commonwealth of Australia. Available at:

http://www.abs.gov.au/ausstats/abs@.nsf/latestProducts/3238.0.55.001Media\%20Rel ease1June $\% 202011$

Behrendt, L. (2006) The urban Aboriginal landscape, in: K/Anderson, R. Dobson, F. Allon and B. Neilson (Eds). After Sprawl: Post-suburban Sydney. E-Proceedings of the 'Post-Suburban Sydney: the City in Transformation' conference (Centre for Cultural Research, University of Western Sydney).

Bird Rose, D. (1996). Nourishing terrains: Australian Aboriginal views of landscape and wilderness, Canberra: Australian Heritage Commission.

Bird Rose, D. (2000). Dingo makes us human: Life and land in an Aboriginal culture. Melbourne: Cambridge University Press.

Darian-Smith, K., \& Hamilton, P. (1994). (Eds.) Memory and history in twentiethcentury Australia. Melbourne: Oxford University Press.

De Bolla, P. (2001). Art matters. Cambridge, MA: Harvard University Press.

Ellsworth, E. (2005). Places of learning: Media, architecture, pedagogy. New York: Routledge.

Gorringe, S. (2010). Honouring our strengths: Moving forward. Keynote Address presented at the 2010 Annual SPERA Conference. Stronger Smarter Institute, 
Queensland University of Technology. Queensland: University of the Sunshine Coast. (September).

Gruenewald, D. (2003). Foundations of place: A multidisciplinary framework for placeconscious education. American Educational Research Journal, 40(3), pp. 619-54.

Jameson, J., Clayton, P.\& Jaeger, A. (2011). Community engaged scholarship as mutually transformative partnerships. In L. Harter, J. Hamel-Lambert \& J. Milleson (Eds.), Participatory partnerships for social action and research (pp 259-277). Dubuque, IA: Kendall Hunt

Jaworski, A. (1997). Metacommunicative and metaphorical silences. In A. Jaworski (Ed.), Silence (pp. 381-402). Berlin: Mouton de Gruyter.

Jeffers, C. S. (2009). Within Connections: Empathy, mirror neurons, and art education. Art Education, 62(2), 18-23.

Kiely, R 2005, ‘Transformative international service---learning', Academic Exchange Quarterly, 9, 275-281.

Krensky, B., \& Steffen, S. L. (2008). Arts-based service-learning: A state of the field. Art Education, 61(4), 13-18.

Lacan, J. (1977). Ecrits: A selection. London: Tavistock.

La Jevic, L. \& Springgay, S. (2008). A/r/tography as an ethics of embodiment: Visual journals in preservice education. Qualitative Inquiry, 14(1), 67-89.

Lawton, P.H. (2010). Hand-in Hand, Building Community on Common Ground. Art Education, 63(6), 6-12.

Lincoln, Y. (1995). Emerging criteria for quality in qualitative and interpretive research. Qualitative Inquiry, 1(3), 275-289. 
McInerney, P., Smyth, J., \& Down, B. (2011). Coming to a place near you: The politics and possibilities of a critical pedagogy of place-based education. Asia Pacific Journal of Teacher Education, 39(1), 3-16.

Mobeley, C. (2011). Diversity and service-learning. In T. Stewart \& N. Webster (Eds.) Exploring cultural dynamics and tensions within service-learning. Charlotte: Information Age Publishing.

Molnar, M. (2010).Arts-based service learning: A curriculum for connecting students to their community. Arizona: University of Arizona.

Moorcroft, H. \& Galwood, A. (Eds.). (1997). Aboriginal and Torres Strait Islander thesaurus. Canberra: National Library of Australia.

Muecke, S. (1984). Introduction. In K. Benterrak, S. Muecke \& P. Roe (Eds.) Reading the country: An introduction to nomadology (p ii). Fremantle: Fremantle Arts Centre Press.

Nancy, J. L. (2000). Of being singular plural, Stanford, CA: Stanford University Press. Ollin, R. (2009). “The silence we create marks out the excellent teacher": A pedagogy of silence in the formal learning environment. Paper presented at The European Conference on Educational Research (ECER), September 2009, Vienna, Austria.

Robertson, B., Demosthenous, C., \& Demosthenous, H. (2005). Stories from the Aboriginal women of the yarning circle: When Cultures Collide. Brisbane: Hecate Press.

Russell, R. L., \& Hutzel, K. (2007). Promoting Social and Emotional Learning through Service-Learning Art Projects. Art Education, 60(3), 6-11.

Shelemay, K. K. (1997). The ethnomusicologist, ethnographic method, and the transmission of tradition. In G. F. Barz \& T. F. Cooley (Eds.), Shadows in the 
field: New perspectives for fieldwork in ethnomusicology (pp. 189-204). New York: Oxford University Press.

Somerville, M. (1999). Body/landscape journals. Melbourne: Spinifex Press.

Somerville, M. (2005). Wildflowering: The life and places of Kathleen McArthur.

Brisbane: University of Queensland Press.

Somerville, M. (2012) Water in a dry land: Place learning through art and story, New York and London: Routledge.

Stachowski, J.J., \& Mahan, J.M. (1998). Cross-Cultural Field Placements: Student

Teachers Learning from Schools and Communities, Theory into Practice, 37 (2), 155-162.

Tacey, D. (1995). Edge of the sacred. Melbourne: Harper Collins.

Thomas, E., \& Mulvey, A. (2008). Using the arts in teaching and learning: Building student capacity for community-based work in health psychology. Journal of Health Psychology, 13, 239-250.

Todd, S. (2003). Learning from the other: Levinas, psychoanalysis, and ethical possibilities in education. Albany: State University of New York Press.

Turner, M. K. (2010). IwenheTyerrte: What it means to be an Aboriginal person. Alice Springs, NT: IAD Press.

UNESCO (2006) Traditional Knowledge http://www.unesco.org/bpi/pdf/memobpi48_tradknowledge_en.pdf (last retrieved: 3 Feb 2013).

Walsh, L.V., \& DeJoseph, J. (2003). "I saw it in a different light": International learning experiences in baccalaureate nursing education. Journal of Nursing Education, $42(6), 266-272$ 
Wright, J. (1985). Landscape and Dreaming. In S. Grabaud (Ed.). Australia: The Daedalus symposium (p.32). Sydney: Angus \& Robertson. 